\title{
The basic helix-loop-helix protein BETA2 interacts with p300 to coordinate differentiation of secretin-expressing enteroendocrine cells
}

\author{
Hiroyuki Mutoh, ${ }^{1}$ Francisco J. Naya, ${ }^{2,3}$ MingJer Tsai, ${ }^{2}$ and Andrew B. Leiter ${ }^{1,4}$ \\ ${ }^{1}$ Division of Gastroenterology, GRASP Digestive Disease Research Center, and Tupper Research Institute, N ew England \\ Medical Center-Tufts University School of Medicine, Boston, M assachusetts; ${ }^{2}$ Department of Cell Biology and M edicine, \\ Baylor College of Medicine, Houston, Texas USA
}

The major epithelial cell types lining the intestine comprise a perpetually self-renewing population of cells that differentiate continuously from a stem cell in the intestinal crypts. Secretin-producing enteroendocrine cells represent a nondividing subpopulation of intestinal epithelial cells, suggesting that expression of the hormone is coordinated with cell cycle arrest during the differentiation of this cell lineage Here we report that the basic helix-loop-helix protein BETA2 associates functionally with the coactivator, p300 to activate transcription of the secretin gene as well as the gene encoding the cyclin-dependent kinase inhibitor p21. Overexpression of BETA2 in cell lines induces both cell cycle arrest and apoptosis suggesting that BETA2 may regulate proliferation of secretin cells. Consistent with this role, we observed both reentry of normally quiescent cells into the cell cycle and disrupted cell number regulation in the small intestine of BETA2 null mice Thus, BETA2 may function to coordinate transcriptional activation of the secretin gene, cell cycle arrest, and cell number regulation, providing one of the first examples of a transcription factor that controls terminal differentiation of cells in the intestinal epithelium.

[Key Words: transcription factor; intestine; enteroendocrine; p300; BETA2; NeuroD]

Received January 8, 1998; accepted January 26, 1998.

The mammalian intestinal tract is lined with a continuously regenerating, perpetually differentiating epithelium. Each of the four principal cell types-enterocytes, enteroendocrine cells, goblet cells, and paneth cellsarises from a relatively small number of totipotent stem cells located near the base of the intestinal crypts. Dividing crypt cells descended from the stem cells migrate up the crypt-villus axis to further differentiate into each of the respective lineages, cease dividing in the villi, and eventually are extruded from the villus tip into the intestinal lumen (Fig. 1). Frequently, the proteins encoded by genes that control spatial and temporal differentiation in complex organisms are transcription factors. Transcription factors that regulate differentiation of intestinal epithelial cells have not been identified. Secretinexpressing enteroendocrine cells represent an attractive model for examining temporal and spatial differentiation in the small intestine (Fig. 1). Secretin cells turnover every 5 days and comprise a small nondi viding subpopu-

\footnotetext{
3Present address: Department of Molecular Biology and Oncology, University of Texas Southwestem Medical Center at Dallas, Dallas, Texas 75235-9148.

${ }^{4}$ Corresponding author.

E-MAIL andy.leiter@es.nemc.org FAX (617) 636-4207.
}

lation of individual endocrine cells found only in the villus epithelium that express a unique gene product, the hormone secretin (Inokuchi et al. 1985).

Members of the basic helix-loop-helix (bHLH) family of transcription factors activate expression of tissue-specific genes in several developmental systems including the myogenic cascade and B-cell differentiation. The bHLH transcription factor BETA2 plays an important role in the devel opment and differentiation of pancreatic and intestinal endocrine cells. BETA2 was first cloned from pancreatic islet cells and identified as an activator of insulin gene transcription ( $\mathrm{N}$ aya et al. 1995). The identical protein, named neuroD, was cloned from embryonic stem cells and identified in neurons of the developing nervous system at the time they differentiate terminally (Lee et al. 1995b). Subsequent studies have shown that BETA2 also functions to activate transcription of the gene encoding the intestinal hormone secretin (Mutoh et al. 1997). BETA2 binds to an E box sequence in the secretin gene heterodimerized to either E12 or E47 ubiquitously expressed bHLH proteins. Gene-targeting experiments disrupting the murine BETA 2 gene suggest an important role for BETA2 in enteroendocrine cell differentiation. Mice lacking a functional BETA2 gene failed 


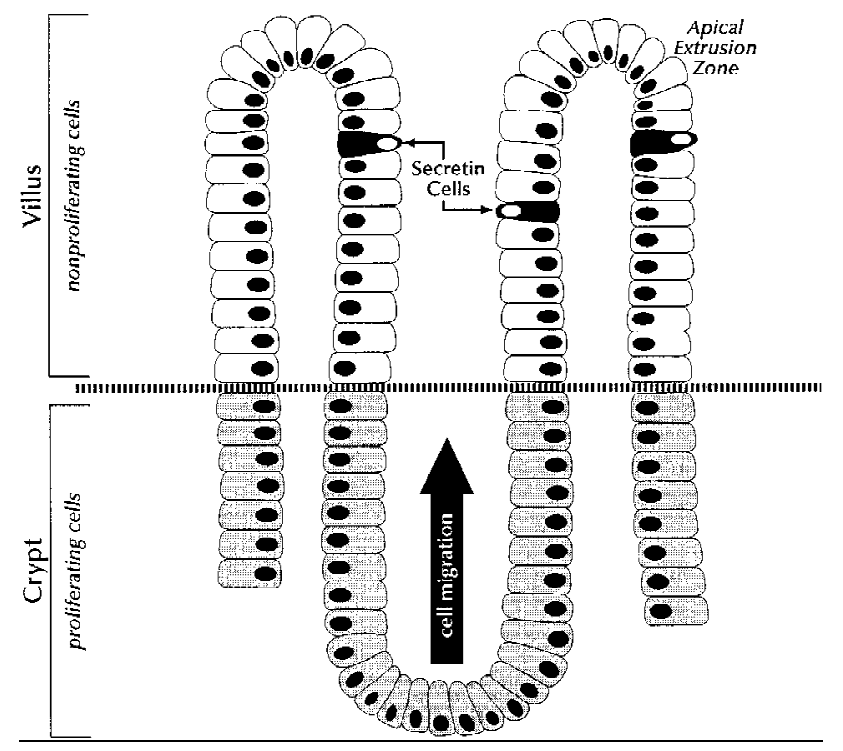

Figure 1. Differentiation of secretin enteroendocrine cells. Schematic view of the small intestine in Iongitudinal section. Intestinal epithelial cells differentiate from an anchored stem cell population in the proliferating crypt compartment. Cells migrate vertically as a band up the crypt-villus axis to differentiate further. Secretin cells differentiate as nondividing, isolated mucosal endocrine cells in the upper villus. Cell loss is believed to occur near the villus tip near the end of the vertical migration pathway.

to develop secretin- and cholecystokinin-expressing cells, whereas the remaining enteroendocrine cell lineages appeared relatively unaffected ( $N$ aya et al. 1997).

The transforming oncoproteins of DN A tumor viruses, such as the adenovirus E1A protein or the large T-antigen (TAg) of SV 40 frequently disrupt cellular differentiation by altering intracellular transcription. Previously, we have shown that expression of SV40 TAg in secretin cells of transgenic mice induces cell cycle reentry and blocks secretin expression in these cells (Lopez et al. 1995). The viral proteins E1A and TAg appear to alter cellular transcription by their ability to complex with nuclear proteins associated with cell cycle control.

One of these proteins, p300, which associates with the amino terminus of E1A, bel ongs to a family of transcriptional coactivators that al so includes the closely related CAMP response element-binding (CREB) protein (CBP) (Chrivia et al. 1993; Eckner et al. 1994). p300/CBP associate with many classes of transcription factors to act as coactivators. These include nuclear receptors (Chakravarti et al. 1996; Kamei et al. 1996), basic leucine zipper (bZIP) proteins including Jun, Fos, CREB (Arias et al. 1994; Chrivia et al. 1993; Lee et al . 1996a,b), STAT proteins (Bhattacharya et al . 1996; Zhang et al . 1996), members of the cREL family (Perkins et al. 1997), bHLH proteins including M yoD (Eckner et al. 1996b; Yuan et al. 1996; Sartorelli et al . 1997), Hif-1 (A rany et al. 1996), and c-Myb (Dai et al. 1996). In addition, p300/CBP interact with TFIIB (Kwok et al. 1994), cyclin-dependent kinasecyclin complexes (Perkins et al. 1997), E1A (Eckner et al.
1994), and SV40 TAg (A vantaggiati et al. 1996; Eckner et al. 1996a). Thus, p300/CBP integrate a wide variety of nuclear signals to control cellular transcription, proliferation, and differentiation.

We have examined whether p300 interacts functionally with BETA2 to promote terminal differentiation of secretin cells. In this report, we show that p300 is a potent coactivator of BETA2-dependent transcription of the secretin gene and p21, an inhibitor of cyclin-dependent kinases. Our results indicate that the bHLH region of BETA 2 interacts with sequences overlapping the E1Abinding domain of p300. BETA2 appears to coordinate transcription of the secretin gene with cell cycle arrest and cell number regulation by apoptosis.

\section{Results \\ p300 coactivates BETA2-dependent transcription of the secretin gene}

To examine whether p300 was involved in transcriptional activation of the secretin gene by BETA2, we used a previously described reporter gene that contains enhancer sequences from -209 to +32 in the secretin gene. This enhancer includes a single $E$ box-binding site for BETA2. When coexpressed transiently in HeLa cells, BETA2 stimulated reporter gene expression 22-fold (Fig. $2 A$, col umn 6). The observed transactivation was specific for BETA2, because the reporter gene was expressed at very low levels al one or with coexpressed E47, a ubiquitous bHLH protein (Fig. 2A, columns 1,3). Cotransfecting increasing amounts of a p300 expression plasmid further potentiated BETA2-dependent transcription to $>100$-fold greater than the reporter alone. The failure of p300 to transactivate the reporter gene in the absence of BETA2 (Fig. 2A, column 2) indicated that p300 specifically activated BETA2-dependent transcription. The effects of p300 on BETA2-dependent transcription did not result from induction of BETA 2 by p300 as the level of BETA2 was unaffected by overexpressing coactivator (Fig. 2B). A s expected, the related protein CBP functioned similarly as a coactivator of BETA2 (not shown). The observed coactivation of BETA2 by p300 suggested that these proteins associate functionally in vivo. We examined cell lysates from BETA2-producing $\beta$ TC 3 cells for p300-associated BETA2. Immunobl otting with a BETA2 antibody identified a $\sim 52-k D$ band corresponding to BETA 2 in proteins precipitated with p300 antibodies but not with control sera (Fig. 2C). The same 52-kD protein was not present in lysates from $\mathrm{HeLa}$ cells that do not express BETA2 (Fig. 2C, lanes 3,4) and was not seen when probed with control antisera (not shown).

We further characterized the role of p300 as a coactivator of BETA2-activated transcription by examining the effects of E1A (Fig. 2D). Cotransfection of increasing amounts of an expression plasmid for E1A $12 S$ repressed luciferase activity generated from the reporter gene in a dose-dependent manner. Overexpression of p300 re versed transcriptional repression by E1A, suggesting that E1A interfered with transcriptional coactivation by 

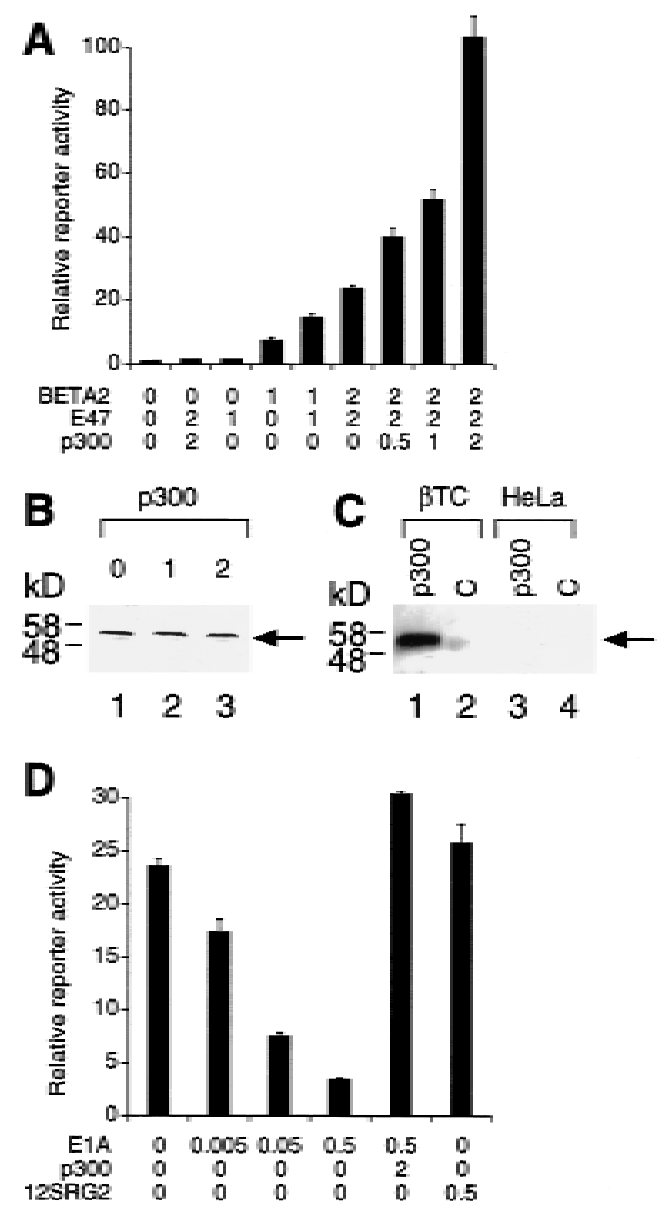

Figure 2. p300 coactivates BETA2-dependent transcription. HeLa cells were transfected transiently with a secretin-luciferase reporter gene and the indicated expression plasmids in the amounts (micrograms) indicated. (A) p300 potentiates transactivation by BETA2. (B) Immunoblot showing expression levels of transfected BETA2 in cells cotransfected with p300. (C) BETA2 immunoblot of proteins immunoprecipitated from $\beta$ TC 3 or HeLa cells with monocl onal antibodies against p300 or normal mouse serum. (D) E1A repression of BETA2-dependent transcription. BETA2 $(2 \mu \mathrm{g})$ and E47 $(2 \mu \mathrm{g})$ expression plasmids were included in the experiments shown in D. Results of transfections are expressed as rel ative luciferase activity compared to cells transfected with the reporter gene al one. Luciferase activity was measured in cell extracts $24 \mathrm{hr}$ after transfection. Values shown represent the mean \pm S.E.M. of at least five individual transfection experiments.

p300. In contrast to wild-type E1A, an E1A mutant, 12SRG2, that harbors a single amino acid substitution at position 2 failed to repress BET A2-dependent transcription. This mutant cannot associate with p300 but retains the ability to interact with members of the RB family of proteins. Thus, the repression of BET A2-dependent transcription by E1A 12 S is specific and depends on the ability of E1A to associate with p300.

Interaction between p300 and BETA2

To determine whether there was a biochemical interac- tion between BETA2 and p300, we examined whether these proteins associate directly using an in vitro-binding assay (Fig. 3A). We expressed the amino-terminal, middle, and carboxy-terminal third of p300 as glutathione S-transferase (GST) fusion proteins in bacteria and generated protein affinity resins by absorption onto glutathione-agarose beads. Full-length BETA2 Iabeled with ${ }^{35}$ S]methionine was synthesized using an in vitro transcription/translation system and tested for its ability to bind to the affinity resins. The fusion containing the carboxy-terminal (amino acids 1572-2370) captured BETA2, whereas GST alone or fusions containing the amino-terminal (amino acids 1-596) or the central portions of the p300 protein (amino acids 744-1571) did not, suggesting that BETA2 associates specifically with the carboxy-terminal third of p300 (Fig. 3A).

BET A 2 binds to DN A heterodimerized to ubiquitously expressed bHLH proteins including E47 or E12, the products of E2A gene to activate transcription. To determine whether ubiquitously expressed bHLH proteins interact with p300, we compared the rodent homolog of E12 (shPan2) synthesized and labeled in vitro (Fig. 3B, lane 2) to BETA2 (Fig. 3A, lane 5) for its ability to bind to the GST -p300 affinity resins. E12 was retained by the GSTp300(amino acids 1572-2370) resin (Fig. 3B), but not by GST alone bound to the resin, or the GST-p300 resins containing the amino terminus or middle region of p300 (not shown). However, E12 bound with relatively low efficiency $(\sim 5 \%)$ compared to BETA2 (Fig. 3, B, lane 2 vs. $A$, lane 5). The relatively weak association of E12 with p300 did not result from in vitro synthesis of a nonfunctional protein as the radiol abel ed E12 appeared to be capable of dimerizing efficiently with BETA2 shown by its retention on a GST-BETA2 affinity resin (Fig. 3B, Iane 3).

The bHLH domain of BETA2 is required for its interaction with p300

To examine the domains of BETA2 required for interaction with p300, we generated a series of BET A 2 deletion mutants. The del etion-bearing mutants were translated and label ed in vitro and tested for their ability to bind to the GST -p300 affinity resin (Fig. 3C,D). The 200 amino acids at the carboxy terminus of BETA2, which includes an activation domain, appear to be dispensable for the interaction between BETA2 and p300 because BETA2 (1-158) was retained by GST-p300. The inability of the mutant $\Delta 49-155$ to bind to p300 indicates that the amino-terminal half of BETA 2 is required for interaction and confirms that the carboxyl terminus of BETA2 does not interact by itself with p300. However, mutants containing del etions encroaching the bHLH region ( $\Delta 49-96$, $\Delta 100-109, \Delta 113-128$, BETA2 (1-138) did not bind to the GST-p300 resin, suggesting that association with p300 requires most, if not all, of the bHLH domain of BETA2. The mutant $\Delta 49-77$, which lacks an acidic domain at the amino terminus of BETA2 bound to the affinity matrix suggesting that the interaction with p300 did not require this region of BETA2. The ability of this latter mutant to 
BETA2-p300 and enteroendocrine differentiation

A

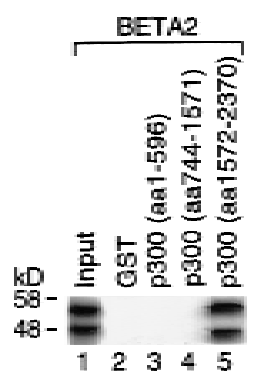

B

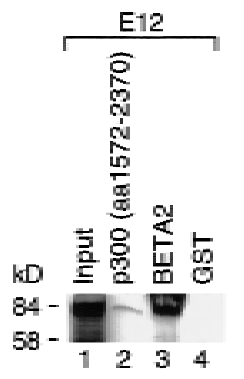

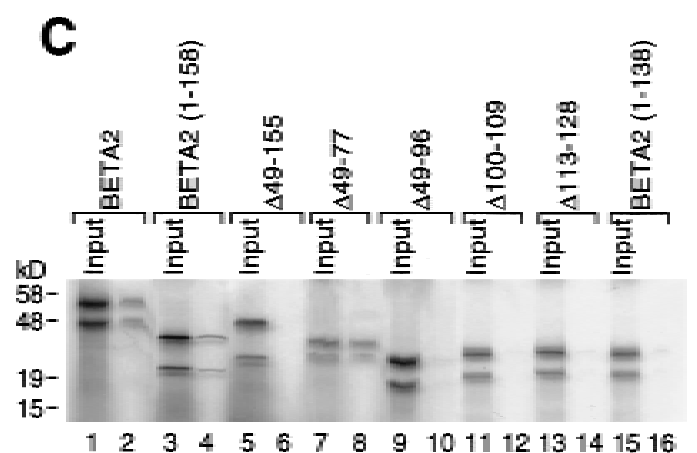

D
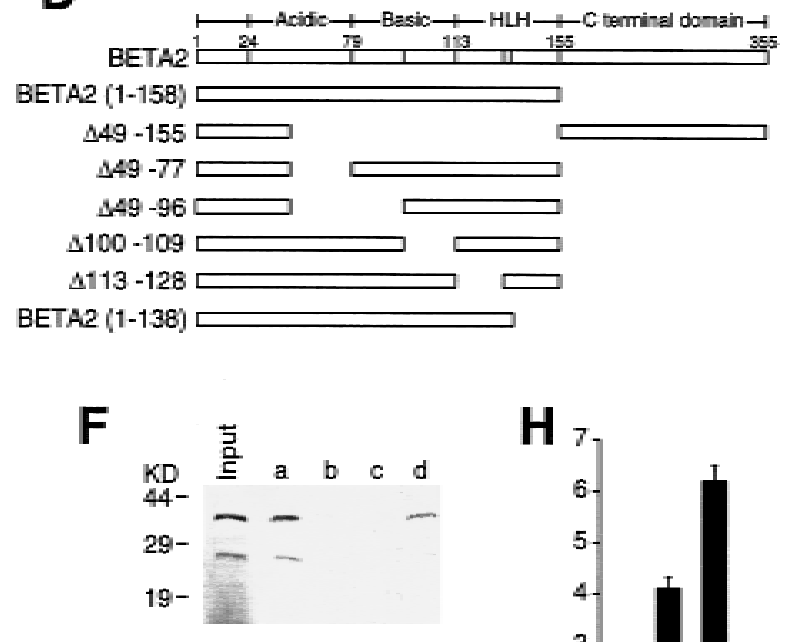

G

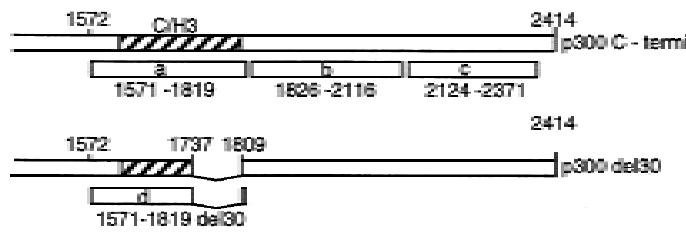

$\mathbf{F}$

H

E

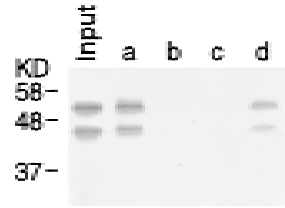

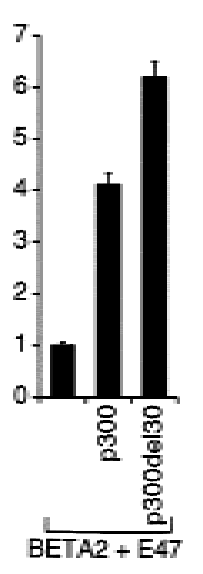

Figure 3. The bHLH domain of BETA2 associates with a domain of p300 that overlaps its E1A-binding site. (A) BETA2 binds to the carboxy-terminal third of p300 in vitro. In vitro-translated, $\left[{ }^{35} \mathrm{~S}\right]-\mathrm{la}$ beled BETA2 was tested for its ability to bind to GST fusion proteins containing the amino-terminal (lane 3), middle (lane 4), and carboxy-terminal third (lane 5) of p300 or GST al one (lane 2). The autoradiograph was exposed for 2 days, using an intensifying screen. (B) Binding of E12 to p300. In vitro-translated ${ }^{35}$ S-labeled E12 was tested for its ability to bind to a GST fusion protein containing either the carboxy-terminal third of p300 (lane 2) or BETA2 (lane 3). (C) In vitro-translated ${ }^{35} \mathrm{~S}$ label ed BETA2 proteins were examined for their ability to bind to amino acids 15722370 of p300 expressed as a GST fusion protein. Odd-numbered lanes show $\sim 10 \%$ of the input protein applied to the affinity matrix; even-numbered lanes show the radiolabeled proteins captured by the GSTp300 affinity matrix. (D) Structure of the BETA 2 proteins used in the binding assay in C. (E,F) Different GST -p300 fusion proteins shown in $\mathrm{G}$ were tested for their ability to capture either ${ }^{35} \mathrm{~S}$-label ed full-length BETA2 (E) or BETA2 (1-158) (F). (H) HeLa cells were transfected transiently with a secretin-luciferase reporter gene, expression plasmids for BETA2 and E47, and either p300 or p300del 30 . Values shown are the mean \pm S.E.M. of at least three independent transfections and represent the relative reporter expression vs. the activity from cells that did not receive a p300 expression vector. bind to p300 suggests that amino acids 78-158 represent the p300 interaction domain of BETA2.

The BETA2-binding domain of p300 overlaps the E1A-binding region of $\mathrm{p} 300$

To localize further the BETA2-binding domain within amino acids $1572-2370$ of the E1A-binding region of p300, we tested additional GST-p300 fusion proteins containing deletions within this region of p300 for their ability to bind to labeled BETA2 (Fig. 3E-G). Fusion proteins containing amino acids 1571-1819 captured the in vitro translated full-length (Fig. 3E, Iane a) and BET A2(1158) proteins (Fig. 3F, lane a), whereas fusions containing amino acids 1826-2116 and 2124-2371 of p300 did not, indicating that amino acids 1571-1819 of p300 are important for BETA2 binding (Fig. 3E,F, lanes b,c). These sequences contain the third Cys/His-rich region of $\mathrm{p} 300$, a region implicated previously in the association of p300 with E1A and possibly MyoD (Fig. 3G).

We further characterized the relationship between the BETA2 and E1A interaction domains of p300 by examining whether either full-length BETA2(1-355) or BET A2(1-158) bound to a GST - p300 fusion protein spanning amino acids 1571-1819 containing an internal deletion of residues $1738-1808$ (Fig. 3G). This del etion in full-length p300del 30 disrupts its interaction with E1A (Eckner et al. 1994). The GST-p300(1571-1819)del30 fusion protein was still capable of binding to either fulllength BETA2 or BETA2(1-158) (Fig. 3E,F, lanes d), suggesting that the BETA2-binding site local izes to approximately amino acids 1571-1737. The full-length p300del 30 protein coactivated BETA2-dependent transcription of the secretin gene, further indicating that the deleted sequences were not required for BETA2-p300 interactions (Fig. $3 \mathrm{H})$. The increased activity seen with the 
p300del 30 protein in HeLa cells may result from reduced association with human papilloma virus E7, which is functionally similar to E1A.

\section{BETA2 and p300 interact in vivo}

Two approaches were used to study the interaction of BETA2 and p300 in vivo. First, we expressed the GST p300 fusion proteins shown to interact with BETA2 in vitro in BET A2-expressing HIT insulinoma cells. Whole cell extracts were mixed with glutathione-agarose beads, the adsorbed proteins separated by SDS-PAGE. Immunobl otting with BETA2 antibodies reveal ed a $~ 52-k D$ band corresponding to endogenous BETA2 that was not captured in cells expressing GST alone (Fig. 4A). These results suggest BETA 2 interacts with amino acids 1572 2116 of p300 in vivo as well as in vitro.

We further characterized the domains of BETA2 that interacted with p300 in vivo using a mammalian two-

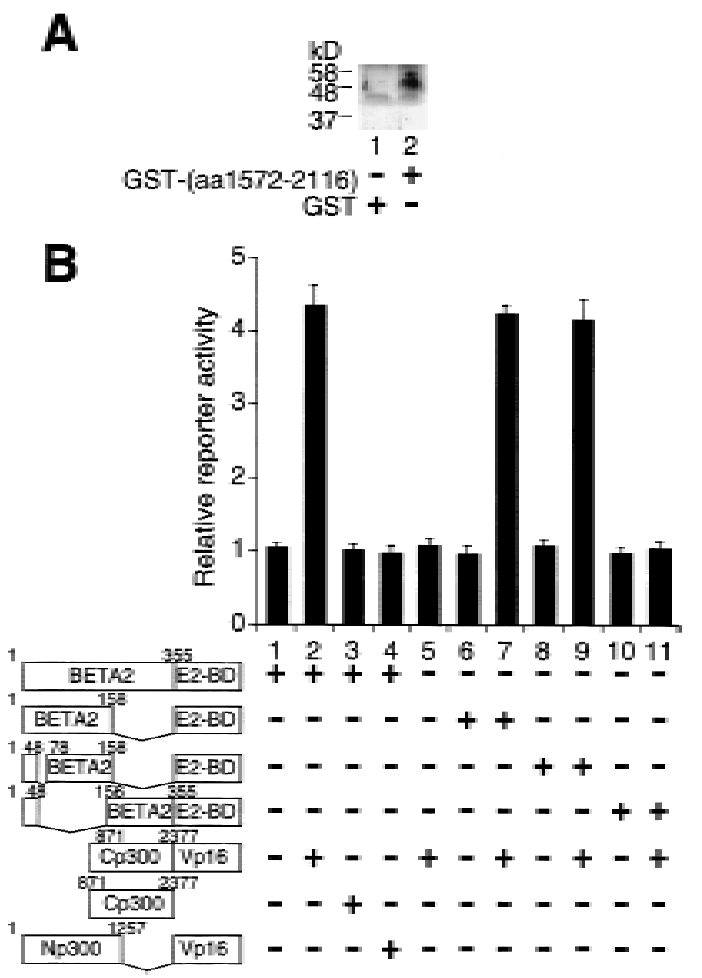

Figure 4. The bHLH domain of BETA2 associates with the carboxyl terminus of p300 in vivo. (A) A GST-p300 fusion protein encoding amino acids 1572-2116 of p300 or GST al one was expressed in HIT cells. Cell extracts were mixed with glutathione-agarose beads and bound proteins examined by immunoblotting for BETA2. (B) A mammalian two-hybrid assay was carried out in HeLa cells cotransfected transiently with expression vectors for one of four BETA2-E2 DNA-binding domain fusion proteins, a p300-VP16 fusion as indicated, and a luciferase reporter containing four copies of an E2-binding site. Luciferase activity was measured $24 \mathrm{hr}$ after transfection and results expressed as activity relative to extracts transfected with the BETA2-E2 fusion plasmid alone. Values shown represent the mean \pm S.E.M. of at least five independent experiments. hybrid assay in HeLa cells (Fig. 4B). BETA2 fused to the DNA-binding domain of bovine papilloma virus E2 was capable of interacting with sequences in the carboxyl terminus of p300 (amino acids 871-2377) fused to the herpes simplex virus VP16 activation domain to increase expression of a cotransfected E2-luciferase reporter gene (Fig. 4B, lanes 1,2 ) as were BETA2 (1-158) and BETA2 (1-158, $\Delta 49-77)$ E2 fusions lacking the carboxy terminal transactivation domain (Fig. 4B, lanes 7,9). In contrast, a BETA2-E2 fusion containing a 107-amino-acid deletion in the bHLH region (BETA2 $\Delta 49-155)$ was unable to recruit the p300-VP16 fusion to activate the reporter (Fig. $4 \mathrm{~B}$, lane 11). These results confirm the importance of bHLH domain of BETA2 for interaction with p300 in vivo, corroborating in vitro-binding data.

The amino-terminal region of p300 (amino acids 11257) fused to the VP16 activation domain ( $\mathrm{N} \mathrm{p300/}$ VP16) did not interact with BETA2-E2 fusion proteins to increase expression E2-luciferase reporter gene (Fig. 4B, lane 4), in agreement with the earlier in vitro-binding studies indi cating that BET A2 associates with sequences in the carboxy-terminal third of p300. VP16 al one did not interact with the BETA2-E2 proteins, failing to increase reporter expression, indicating the requirement for p300 for recruitment to the BETA2-E2 fusion (not shown). Additional controls revealed that recruitment of $\mathrm{Cp} 300$ VP16 depended on BETA2, as this fusion failed to interact with the E2-binding domain in the absence of BETA2 sequences to activate the E2-luciferase reporter (Fig. 4B, lane 5). Taken together, characterization of p300-BETA2 interactions in vivo confirm the observations from the GST affinity matrix assays indicating that the carboxyterminal region of p300 associates with the bHLH region of BETA2.

BETA2 inhibits cell proliferation and induces apoptosis

Induction of the cyclin-dependent kinase inhibitor p21 by p300 is one mechanism by which both p300 and the myogenic bHLH protein MyoD influence cell proliferation and terminal differentiation (Halevy et al. 1995; Missero et al. 1995). To determine whether BETA2 influences expression of p21, we examined whether BETA 2 regulates transcription of the p21 gene. A luciferase reporter gene under control of regulatory sequences in the p21 gene was transfected transiently into HeLa cells al ong with expression plasmids for BETA2 and p300 (Fig. 5A). BET A 2 activated the p21 reporter gene suggesting that the p21 gene represents another target of BETA2. Cotransfecting a p300 expression plasmid further potentiated BETA2-dependent transcription of the p21 gene (Fig. 5A, column 6). Repression of BETA2-dependent transcription of the 221 gene by E1A, as well as the ability of p300 to overcome the effects of E1A, further suggests that $p 300$ functions as a coactivator of the $p 21$ gene (Fig. 5A, columns 4,5).

To determine whether induction of p21 by BETA 2 correlated with cell proliferation control, we transfected 
A

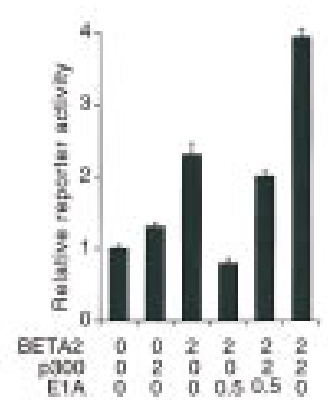

B

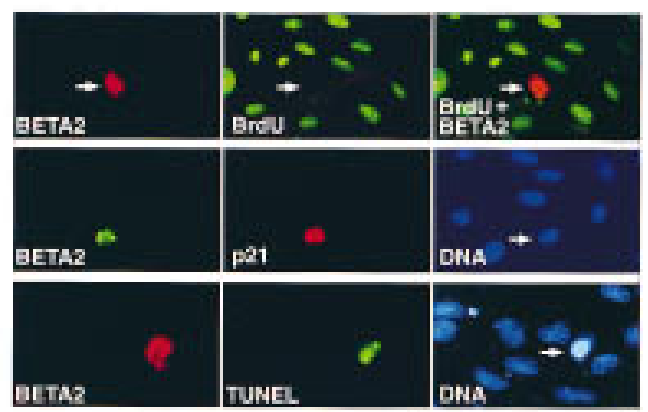

Figure 5. BETA2 induces expression of p21, cell cycle arrest, and apoptosis. (A) BETA 2 and p300 increase $p 21$ gene expression. HeLa cells were cotransfected with a p21-luciferase reporter plasmid and with expression plasmids for BETA2, p300, and E1A as indicated. Results are expressed as luciferase activity relative to the activity seen in extracts of cells transfected with the reporter gene al one. Luciferase activity was measured in cell extracts $24 \mathrm{hr}$ after transfection. Values represent the mean \pm S.E.M. of at least five individual experiments. (B) CV-1 cells were transfected with influenza virus hemaglutinin epitope-tagged BETA 2 and examined for BrdU incorporation (top row), p21 coexpression (middle row), and apoptosis by TUNEL assay (bottom row). (Top row left A single cell expressing HA-BETA2 localized with a cy3-conjugated secondary antibody; (middle) staining for BrdU localized with a FITC-conjugated primary antibody; (right) a multiple exposure photomicrograph confirming absence of BrdU incorporation in the cell expressing HA-BETA2. Induction of p21 is shown in the middle row. A single cell is seen coexpressing HA-BETA2 (left) and p21 (middle) localized with a FITC- and cy3-conjugated secondary antibodies. DN A staining of the same section with Hoechst dye (right). The arrow denotes cells expressing BETA2. (Bottom row) A single cell expressing HA-BETA2 (cy3, left) undergoing apoptosis by TUN EL assay (FITC, middle). DN A staining of the same section with Hoechst dye (right). The arrow denotes cell expressing BETA2.

CV1 cells with an expression plasmid for epitope-tagged BETA2 (CMV-HA-BETA2) and examined transfected cells for DNA synthesis and p21 induction. Transfected cells expressing BET A2 failed to synthesize new DNA in contrast to the nontransfected CV1 cells, all of which appeared to incorporate BrdU (Fig. 5B, top row). As expected, CV1 cells synthesize DNA actively. However, none of the transfected cells expressing BETA2 (top row, middle and right) incorporated BrdU, indicating cell cycle arrest. Transfected BETA2 induced expression of the endogenous p21 gene to levels that were readily detectable by immunostaining (Fig. 5B, middle row). M ost, if not all, transfected cells showed p21 staining, whereas the untransfected cells did not, indicating a potential role for p21 in mediating the cell cycle inhibition by BETA2. Transfected cells frequently exhibited nuclear condensation when examined by DN A staining (Fig. 5B, bottom row, right), suggesting that cells expressing BETA2 are undergoing programmed cell death. TUNEL assays confirmed that the transfected CVI cells were often undergoing apoptosis (lower row) in contrast to the untransfected cells that failed to stain in these assays. Cells transfected with a p21 expression plasmid did not stain in TUNEL assays (not shown), indicating that the ability of BETA2 to induce apoptosis did not result from its induction of p21. The effects of BETA2 on BrdU uptake, p21 expression, and apoptosis were not seen with p300 al one, transactivation defective mutants of BETA2, or when an unrelated protein, human growth hormone, was overexpressed instead of BETA2 (not shown).

We have examined the role of BETA2 in cell cycle arrest in vivo in transgenic mice lacking a functional BETA2 gene described previously. The BETA2 gene was disrupted by replacing most of the coding sequence with the bacterial lacZ gene containing a nuclear local ization signal. Expression of the BETA2- $\beta$-galactosidase fusion protein allowed us to identify cells that normally would express BETA 2 in animals that were either homozygous or heterozygous for the disrupted allele. In newborn BETA2 +/-mice, which develop normal secretin cells, most cells expressing $\beta$-gal actosi dase showed immunostaining for p21 but rarely expressed PCN A, thus demonstrating normal cell cycle arrest (Fig. 6A, right; Table 1). In contrast, $\beta$-galactosidase-expressing cells in the BETA2 $-1-$ animals stained for PCNA, indicating that they fail ed to exit the cell cycle with most cells staining. In addition, most $\beta$-gal + cells in the homozygous mice failed to stain for p21 as opposed to the heterozygous animals, suggesting that expression of p21 may belinked to normal cell cycle arrest (Fig. 6A, left; Table 1).

Whether BETA2 is involved in inducing apoptosis as part of the normal turnover of intestinal secretin cells, mice lacking a functional BETA2 gene would be expected to show al tered cell number regulation. The number of cells expressing $\beta$-galactosidase in BETA2 $-1-$ mice was compared to BETA2 $+/$-animals by counting the number of X-gal-stained cells per unit length of small intestine. Approximately three times as many cells stained for $\beta$-galactosi dase activity in BETA2 $-1-$ mice versus the BETA $2+/$-animals, suggesting that cell number regulation was indeed disrupted (Fig. 6B).

\section{Discussion}

The intestinal epithelium is a perpetually self-renewing model for differentiation characterized by the generation of multiple cell lineages from a common stem cell population. Cellular differentiation and proliferation occur in spatially defined patterns throughout the intestinal tract. Relatively little is known about the transcriptional 
Figure6. Altered cell cycle arrest and cell number regulation in the small intestine of BETA2 null mice. (A) Immunostaining for PCN A and p21 in the small intestine of 2-day-old BETA2 -1 -and $+1-$ mice stained for $\beta$-galactosidase activity. $N$ ote brown DAB staining for PCNA colocalized with blue nuclear X-gal staining in $-1-$ mice indicating cell cycle reentry not seen in $X$ gal-stained cells of heterozyous mice (top row). N ote loss of peroxidase staining for p21 in X-gal-stained cells of $-1-$ mice (bottom row). Insets show magnified view of cells denoted by arrows. (Bar) $10 \mu \mathrm{m}$; (insets) $6 \mu \mathrm{m}$. (B) The number of stained cells was counted in longitudinal sections of small intestine from three mice from each group. Results were expressed as the mean \pm S.E.M.per $100-\mu \mathrm{m}$ intestinal length. Approximately threefold more $\beta$-gal-positive cells were present in the $t-$ mice ( $P<0.02$, two-sided Student's t-test).
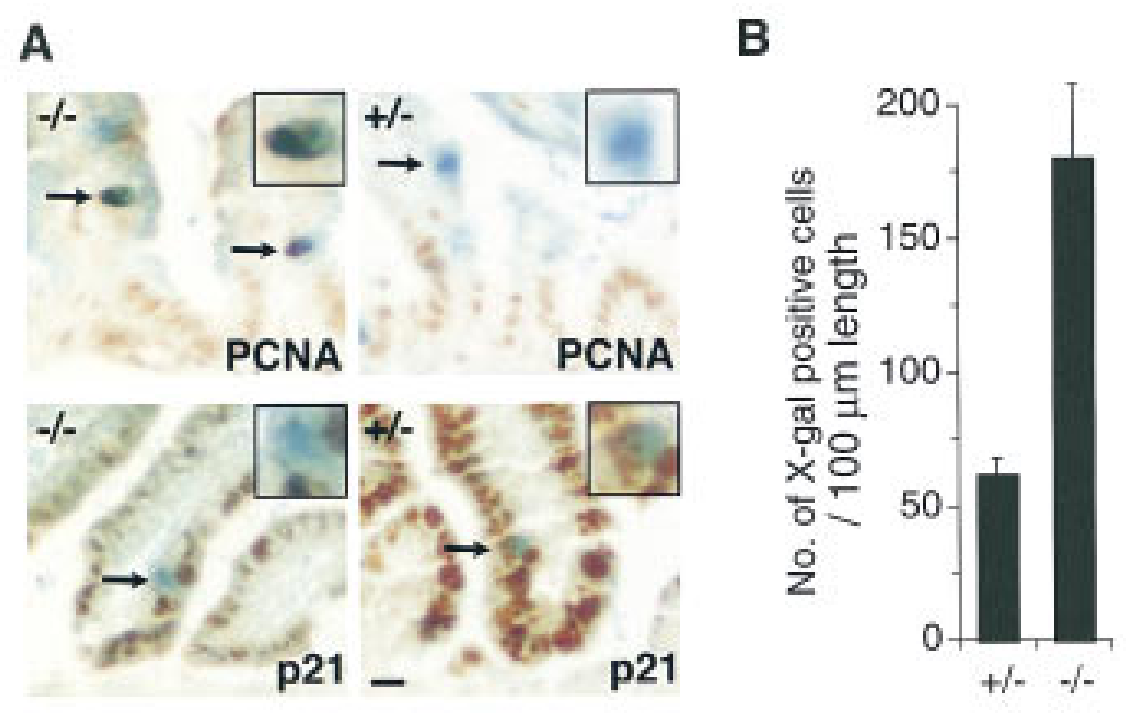

events controlling the segregation and differentiation of the approximately eight different enteroendocrine cell types that have been identified on the basis of their distinct neuroendocrine gene products. Secretin cells are localized exclusively in the nondividing villus compartment. Tritiated thymidine-labeling studies confirm that cells staining for secretin immunoreactivity are a nonproliferating population (Inokuchi et al. 1985). These observations suggest that expression of secretin is coordinated with cell cycle arrest during terminal differentiation of S-type enteroendocrine cells. Gene targeting experiments indicate that the bHLH protein BETA2 is essential for expression of the secretin gene during terminal differentiation of secretin cells.

Here we show that a single bHLH transcription factor BETA2 is capable of regulating critical events in the differentiation of secretin-producing enteroendocrine cells. In addition to activating secretin gene expression, BETA2 appears to induce cell cycle arrest and apoptosis when introduced into cell lines. Gene targeting experiments reveal ed that in the absence of BETA2, nonproliferating cells reenter the cell cycle and that controls Iimiting the number of secretin cells are disrupted, indicat-

Table 1. Loss of p21 expression and cell cycle reentry in enteroendocrine cells of BETA2 $-1-$ mice

\begin{tabular}{lrr}
\hline & \multicolumn{3}{c}{ BETA2 } \\
\cline { 2 - 3 } & $\begin{array}{c}H- \\
(\%)\end{array}$ & $\begin{array}{r}+- \\
(\%)\end{array}$ \\
\hline${\mathrm{p} 21^{+}}^{+}$ & 3.2 & 80.2 \\
$\mathrm{PCNA}^{+}$ & 85.3 & 5.4
\end{tabular}

X-gal-stained sections were immunostained for either p21 or PCN A. At least $90 \beta$-gal-positive cells were examined for either PCNA or p21 immunostaining in 2-day-old $-1-$ or +- mice. ing that BETA2 may control both cell proliferation and cell number regulation in vivo. Thus, BETA2 represents the first identified transcription factor that regulates the differentiation of an epithelial cell type in the intestine.

The present work shows that BETA2 interacts with the transcriptional coactivator $\mathrm{p} 300$. In addition to functioning as a transcriptional adapter molecule, p300 is involved in the control of cell proliferation. One proposed mechanism for $\mathrm{p} 300$ to modulate cell proliferation involves increased expression of the cyclin-dependent kinase inhibitor p21. Keratinocyte differentiation coincides with the induction of p21, which appears to be dependent on functional p300 activity (M issero et al. 1995). Cell cycle arrest during myogenic differentiation is similarly associated with induction of p21 by the bHLH protein MyoD (Halevy et al. 1995). Subsequent studies have clearly establi ished that p300 is required for MyoD-dependent cell cycle arrest (Puri et al. 1997).

Although p21 expression appears in enterocytes as they exit the proliferative compartment of the intestine in the upper crypts, the specific factors responsible for this induction have not been identified (El-Deiry et al. 1995). In the present work we show that BETA2 and p300 activate transcription of the endogenous p21 gene. We believe that induction of p21 by BETA2/p300 coordinates terminal differentiation of secretin cells with their withdrawal from the cell cycle.

The intestinal epithelium is replaced every 3-4 days in rodents. Although the enormous proliferative potential of the intestine is well characterized, considerably less is known about massive cell loss that is critical for cell number regulation. Shedding of epithelial cells from the villus tip is widely accepted as the mechanism underlying cell loss during epithelial self renewal. Recently, apoptosis has been suggested to play a major role in the regulation of epithelial cell number and the importance of exfoliation has been questioned (Hall et al. 1994). 
Small numbers of apoptotic cell bodies ( 1 per villus) are seen throughout the crypt villus axis of the normal rodent small intestine. Villus apoptotic cells were found more frequently near the tip at the end of cell migration pathways. It has been estimated that apoptotic bodies are cleared rapi dly, within 1-2 hr, perhaps accounting for the very small numbers seen histologically (Hall et al. 1994). Because secretin cells comprise a very small percentage of intestinal epithelial cells, it is not feasible to directly demonstrate a change in apoptosis, al though the striking increase in BETA2-expressing cells suggests that the normal loss of secretin cells that occurs during epithelial self renewal is altered.

Little is known about how the size of specific subpopulations of cells in the intestinal epithelium are maintained. The ability of BETA2 to induce apoptosis suggests a role for this factor in the rapid turnover of secretin cells and the regulation of the number of secretin cells. bHLH proteins have not been implicated thus far in the control of apoptosis. BETA2 appears to be a potent inducer of apoptosis whose effects outweigh potential effects of p21 to inhibit programmed cell death as described for differentiating myoblasts (Wang and Walsh 1996). Mice lacking a functional BETA2 gene showed increased numbers of cells staining for DNA fragmentation in the developing pancreas. However, development of the endocrine pancreas depends on a regulatory cascade of transcription factors in addition to BETA2, including Isl-1, PDX-1, Pax4, and Pax 6, Jonsson et al. 1995; Ahlgren et al. 1997; Sosa-Pineda et al. 1997; St-Onge et al. 1997), making it difficult to ascertain whether BETA2 has a direct effect on pancreatic cell loss in animals with markedly abnormal islet morphogenesis. The relatively high frequency of apoptotic cell bodies seen in $\beta$-cells during neonatal development suggests that BET A 2 may have a role in remodeling of islet $\beta$-cells during normal development (Scaglia et al. 1997).

The secretin gene enhancer contains a single $E$ box that functions as a BETA2-binding site. p300 is able to cooperate functionally with BETA2 to transactivate expression from a single $E$ box in the secretin enhancer. Several studies have shown that p300 coactivates transcription from multiple $E$ boxes in muscle-specific and immunoglobulin heavy chain enhancers, by $M$ yoD and E47, respectively (Eckner et al. 1996b; Yuan et al. 1996; Sartorelli et al. 1997). Although it was suggested previously that the two adjacent $E$ box motifs were required for p300 coactivation of bHLH proteins, the present work with the native secretin enhancer shows that a single $\mathrm{E}$ box is sufficient in the appropriate context.

These studies show that the bHLH domain of BETA2 interacts with a region in p300 that overlaps with sequences known to interact with the E1A protein. The ability of E1A to repress BET A2-dependent transcription provides further evidence that p300 interacts functionally with BETA2. Theability of the 300 del 30 mutant to coactivate BETA2 suggests that the E1A and BETA2binding sites are functional ly distinct despite their proximity.

Examination of the role of p300 in activation of the secretin gene described here provides additional information about how bHLH proteins interact with members of the p300/CBP family. We have localized the p300 interaction domain of BETA2 to $~ 80$ amino acids, encompassing its bHLH domain. The carboxy-terminal 200 amino acids, which include an activation domain, appear dispensable as is an acidic domain near the amino terminus of BETA2. In contrast to many other classes of transcription factors that associate with p300 through a transcription activation domain, the DNA-binding/dimerization bHLH motif appears to serve this function for bHLH proteins like BETA2 and possibly M yoD.

Functional interactions between p300 and bHLH proteins to activate transcription have been shown only re cently, with $M$ yoD being studied in greatest detail. The specific domains of $M$ yoD and p300 required for their association has not been well established. Like BETA2, $M y o D$ appears to associate with the region of p300 that interacts with E1A (Yuan et al. 1996). The importance of interactions with the E1A-binding region has been questioned recently as a result of the ability of a p300 mutant del30, which does not complex with E1A, to coactivate $M$ yoD transactivation. Furthermore, $M$ yoD was shown to associate with the amino acids 1-596 of p300 in an in vitro binding assay (Sartorelli et al. 1997). In the present work, we were unable to demonstrate that the aminoterminal half of p300 interacted with BETA2, either in vitro or in vivo. When examined by either an in vitrobinding assay or by coactivation assays, the bHLH domain of $M$ yoD appeared to suffice for association with p300 much like BET A2 (Eckner et al. 1996b). In contrast, others have shown that the amino-terminal 53 amino acids of $M y o D$, which include an acidic domain, appeared to confer the ability of the Gal4 DNA-binding domain to associate with p300 with the HLH domain being dispensable (Sartorelli et al. 1997). Our results indicate that a corresponding acidic sequence near the amino terminus of BETA2 did not appear to interact with p300.

bHLH proteins often bind to DNA as heterodimers to activate tissue-specific genes. Often, one member of the pair is a tissue-specific bHLH protein like BETA2 or $M$ yoD, whereas the other is found in most tissues. The relative importance of p300 interactions with tissue-specific bHLH proteins versus ubiquitous bHLH proteins is not known. We have observed that E12 binds to p300, as has been previously shown (Sartorelli et al. 1997). However, we observed that the interaction between E12 and p300 was at least 50-fold less efficient than BETA 2 and p300 in vitro and we were unable to demonstrate direct binding of E47 to p300. This observation indicates that cell-specific expression may depend on the ability of p300 to interact with tissue-specific bHLH proteins.

In B-cells, E12 and E47 homodimers bind to three E boxes in the immunoglobulin heavy chain enhancer to activate B-cell differentiation. However, p300 efficiently coactivates $\mathrm{E} 47$ homodimers bound to the IgH enhancer (Eckner et al. 1996b). The bHLH domain of E47 is sufficient for this interaction to occur. Furthermore, p300 was much less effective in augmenting transcription of a 
multimeric muscle-specific $\mathrm{E}$ box with $\mathrm{E} 47$ than $\mathrm{M}$ yoD. Thus, the efficiency of E47-p300 interactions may be context specific, with increased interaction when E47 homodimers are bound to the IgH enhancer.

\section{Materials and methods}

Plasmids

Plasmids encoding BETA 2 proteins with truncations and/or deletions [BETA2(1-158), $449-155, \Delta 49-77, \Delta 49-96, \Delta 100-109$, $\Delta 113-128$, BETA2(1-138)] were generated by site-directed mutagenesis from a single-stranded template prepared from a previously described BETA2 in vitro translation plasmid.

To express fragments of p300 as GST fusion proteins in Escherichia coli, sequences encoding amino acids 1571-1819, 18262116, and 2124-2371 in human p300 were amplified with BamHI and EcoRI sites at the $5^{\prime}$ and $3^{\prime}$ ends, respectively, to allow subcloning in the correct reading frame with GST in pGEX-3X (Pharmacia). GST fusions containing an internal deletion of amino acids 1738-1808 from p300 were generated by amplifying sequences from the p300 mutant del30, using the same oligonucleotides as described in the preceding sentence. To generate the plasmid to express amino acids 1572-2116 of p300 as a GST fusion in HIT cells, the sequences encoding the corresponding GST-p300 fusion were amplified from the prokaryotic vector as an Xhol-EcoRI fragment and inserted into the Xhol-EcoRI site of pcDNA3.1(-) (Invitrogen). A plasmid encoding a GST-BETA 2 fusion was generated by introducing a BamHI site by PCR at the amino terminus of BETA2 to allow subcloning a BamHI-EcoRI fragment into pGEX-3X in-frame with GST.

Plasmids encoding BETA2 proteins fused at their carboxyl terminus to the DNA-binding domain of the BPV E2 protein were generated from each of corresponding in vitro transcription/translation plasmids (full-length, BETA2 1-158, BETA2 1-

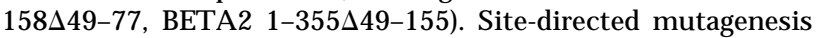
was used to introduce a translationally silent mutation to inactivate an internal $\mathrm{Kpnl}$ site in BETA2 and at the same time to introduce a Kpnl site near the carboxyl terminus of BETA2. The BETA2-encoding sequences from each mutant were excised with BamHI-Kpnl to allow subcloning in-frame with the E2 sequences in the corresponding sites of pCGE2NR encoding amino acids 162-410 of E2 (E. Androphy, unpubl.).

The expression plasmids for BETA2, E47, p300, E1A, E1A12SRG2, and pCMV-BETA2, pCMV-E47, CMV $\beta$-p300, CMV12SE1A , CMV $\beta-12 S R G 2$, and have been described previously. The shPan 1 (hamster E47) and shPan2 (hamster E12) in vitro transcription translation plasmids have been published.

The three GST -p300 plasmids containing amino acids 1-596, 744-1571, and 1572-2370 in-frame with GST-moiety in the pGEX-2TK vector were provided by $\mathrm{Y}$. Shi (Harvard Medical School, Boston, M A). The Cp300/VP16 plasmid encodes amino acids 871-2377 of p300 fused to the VP16 activation domain, the N p300/VP16 plasmid encodes amino acids 1-1257 of p300 fused to the VP16 activation domain, and the Cp300 plasmid, provided by $\mathrm{Y}$. Shi, have been previously reported (Lee et al. 1995a).

A secretin-luciferase reporter plasmid containing one copy of the secretin-enhancer spanning from -209 to +32 has been described. Luciferase reporter genes under control of four copies of an E2-binding site or the p21 gene have been described elsewhere.

\section{Cell lines and transfections}

HeLa and HIT cells were grown in Dulbecco's modified Eagle medium (DMEM) supplemented with $10 \%$ heat-inactivated fetal calf serum and transfected by the cal cium phosphate precipitation (Mutoh et al. 1997). A metallothionine-human growth hormone plasmid $(0.4 \mu \mathrm{g})$ was included in the precipitates to control for variability in transfection efficiency. The total amount of DNA was adjusted with the salmon testis carrier DNA to be identical for each transfection. Cells were harvested $24 \mathrm{hr}$ after addition of the precipitate.

\section{Histochemistry}

CV1 cells on coverslips were fixed in $4 \%$ formalin. For immunostaining, cells were incubated with a monoclonal antibody 12CA5 against influenza virus (hybridoma supernatant, 1:200) and in some cases with a p21 antiserum (Pharmingen; rabbit, 1:600) overnight at $4^{\circ} \mathrm{C}$. Slides were incubated with appropriate secondary antisera conjugated to either cy3 or FITC (Jackson Immunoresearch) for $2 \mathrm{hr}$ at $22^{\circ} \mathrm{C}$. For examination of the effects of BETA2 on cell proliferation, cells were transfected with an expression vector encoding HA epitope-tagged BETA2. Thirty-six hours later cells were incubated with 5-bromo-2'deoxyuridine (BrdU; $10 \mu \mathrm{M}$ final concentration) for additional 12 hr. After localization of cells expressing HA-BETA2 with Cy3conjugated donkey anti-mouse IgG, cells were subjected to a second fixation followed by denaturation in $2 \mathrm{~N} \mathrm{HCl}$. BrdU immunostaining was detected with a monoclonal anti-BrdU conjugated to FITC (BM G 6H8; Boehringer M annheim). Cells were examined for BETA2-induced apoptosis $48 \mathrm{hr}$ after transfection using a fluorescein-based TU N EL assay (Boehringer $M$ annheim) according to the manufacturers' instructions. Cells were immunostained subsequently for HA-BETA2 using a cy3-conjugated secondary antibody for detection. Nuclear DNA was detected with Hoechst dye 33258. Sections were visual ized with the appropriate barrier filters for each fluorophore. Nontransfected cells served as controls to verify the effects of transfected HABETA2. A pproximately $2,000 \mathrm{CV} 1$ cells were examined per coverslip.

Intestinal tissue from BETA $2-1-$ and $+/-$ mice was fixed and stained for $\beta$-gal actosi dase activity, embedded, and sectioned at $4 \mu \mathrm{m}$ as described previously ( $\mathrm{N}$ aya et al. 1997). After microwave antigen retrieval, sections were immunostained with a monoclonal antibody against PCNA (Sigma; 1:3000) or for p21 as described earlier. Primary antibodies were detected by immunoperoxidase using DAB as a substrate.

\section{Luciferase assays}

Whole cell extracts were prepared from the transfected cells with $1 \%$ Triton $\mathrm{X}-100$ and $100 \mathrm{~mm}$ potassium phosphate $(\mathrm{pH}$ 7.8) and $1 \mathrm{~mm}$ dithiothreitol. Enzymatic assays measuring luciferase activity were performed in a M onolight 2010 luminometer (Analytical Luminescence Laboratory). To account for variations in cell transfection efficiency, luciferase activity in cell lysates was normalized to the production of human growth hormone measured by radioimmunoassay ( $\mathrm{N}$ ichols Institute, San Juan Capistrano, CA).

\section{In vitro transcription and translation}

Radiolabeled BETA2 and mutant BETA2 proteins were transcribed and translated in vitro from plasmid templates using a TNT-reticulocyte lysate system (Promega) with either T 7 or T3 RN A polymerase and ${ }^{35}$ S]methionine (DuPont NEN) according to the procedures described by the supplier. 


\section{Coimmunoprecipitation}

BTC3 and HeLa cell lysates were centrifuged at $14,000 \mathrm{~g}$ for 10 $\mathrm{min}$ to pellet debris. After preclearing for $30 \mathrm{~min}$ with protein $\mathrm{G}$-agarose (Boehringer $\mathrm{M}$ annheim), the supernatant was incubated for $1 \mathrm{hr}$ at $4^{\circ} \mathrm{C}$ with monoclonal anti-p300 antibody (CT Power Clone, U pstate Biotechnology) or normal mouse serum. Immune complexes were collected with protein G-agarose beads and analyzed by SDS-PAGE. Separated proteins were transferred to nitrocellulose filters and immunoblotted with anti-neuroD/BET A2 polyclonal antibody (N -19, Santa Cruz Biotechnology).

\section{Binding analysis with GST fusion proteins}

Plasmids encoding GST fusion proteins were expressed in E. coli, adsorbed to glutathione-agarose beads (Pharmacia), washed, mixed with ${ }^{35} \mathrm{~S}$-labeled proteins, and washed as described previously. Bound proteins were released by boiling in SDS sample buffer and analyzed by SDS-PAGE followed by autoradiography. For in vivo GST-binding assays HIT cells were transfected with expression plasmids encoding either a fusion protein GST-p300 (amino acids 1572-2116) or GST al one. Cells were lysed $24 \mathrm{hr}$ after addition of the precipitate in lysis buffer [50 mM HEPES (pH 7.7), $75 \mathrm{~mm} \mathrm{KCl,} 0.1 \mathrm{~mm}$ EDTA, $2.5 \mathrm{~mm}$ $\mathrm{M} \mathrm{gCl}_{2}, 1 \mathrm{~mm}$ DTT, $0.5 \% \mathrm{~N} \mathrm{P}-40$ ] for $20 \mathrm{~min}$ on ice. Cell extracts were rocked for $2 \mathrm{hr}$ at $4^{\circ} \mathrm{C}$ with $80 \mu \mathrm{l}$ of gl utathione-Sepharose beads (Pharmacia). The beads were washed five times with $1 \mathrm{ml}$ of PBS, and eluted with Laemmli sample buffer. After SDSPAGE, proteins were transferred to nitrocellulose filters and probed with an affinity purified anti-neuroD/BETA2 polyclonal antibody. The antibody $\mathrm{N}-19$ is directed against amino acids 29-47 of BETA2 (Santa Cruz Biotechnology).

\section{Mammalian two-hybrid expression assays}

Two-hybrid expression assays for characterizing interactions of p300 with BETA2 in vivo were carried out in HeLa cells transfected transiently with $1 \mu \mathrm{g}$ of a luciferase reporter plasmid containing four E2-binding sites. Cells were cotransfected with $1 \mu \mathrm{g}$ of Cp300VP16, N p300VP16, or Cp300 plus $0.2 \mu \mathrm{g}$ of the E2 $\mathrm{BD}$ plasmid or one of the three BETA2-E2BD fusions as indicated. Cells were harvested $24 \mathrm{hr}$ after transfection and extracts assayed for luciferase activity.

\section{Acknowledgments}

We thank A. Yee and L. G. M oss for hel pful discussions. We al so thank David Livingston, S. Bhattacharya, Richard Eckner, Kenneth Walsh, Yang Shi, and Elliot Androphy for generously providing plasmids and DN A constructs. This work was supported in part by N ational Institutes of Health (NIH) (grant DK43673), the GRASP Digestive Disease Center (grants P30-DK34928 to A.B.L. and HD17379 to M.J.T.), by a grant from the Juvenile Diabetes Foundation International (to A.B.L.). H.M. was supported by a fellowship from Harold Whitworth Pierce Charitable Trust and The Medical Foundation, Inc. (Boston, MA.).

The publication costs of this article were defrayed in part by payment of page charges. This article must therefore be hereby marked "advertisement" in accordance with 18 USC section 1734 solely to indicate this fact.

\section{References}

A hlgren, U., S.L. Pfaff, T.M. Jessell, T. Edlund, and H. Edlund. 1997. Independent requirement for ISL1 in formation of pancreatic mesenchyme and isl et cells. Nature 385: 257-260.
Arany, Z., L.E. Huang, R. Eckner, S. Bhattacharya, C. Jiang, M.A. Goldberg, H.F. Bunn, and D.M. Livingston. 1996. An essential role for p300/CBP in the cellular response to hypoxia. Proc. Natl. Acad. Sci. 93: 12969-12973.

Arias, J., A.S. Alberts, P. Brindle, F.X. Claret, T. Smeal, M. Karin, J. Feramisco, and M. Montminy. 1994. Activation of CAMP and mitogen responsive genes relies on a common nuclear factor. Nature 370: 226-229.

Avantaggiati, M.L., M. Carbone, A. Graessmann, Y. N akatani, B. Howard, and A.S. Levine. 1996. The SV 40 large T antigen and adenovirus Ela oncoproteins interact with distinct isoforms of the transcriptional co-activator, p300. EMBO J. 15: 2236-2246.

Bhattacharya, S., R. Eckner, S. Grossman, E. Oldread, Z. Arany, A. D'Andrea, and D.M. Livingston. 1996. Cooperation of Stat2 and $\mathrm{p} 300 / \mathrm{CBP}$ in signalling induced by interferon-alpha. Nature 383: 344-347.

Chakravarti, D., V.J. LaM orte, M.C. N elson, T. N akajima, I.G. Schulman, H. Juguilon, M. Montminy, and R.M. Evans. 1996. Role of CBP/P300 in nuclear receptor signalling. Nature 383: 99-103.

Chrivia, J.C., R.P. Kwok, N. Lamb, M. Hagiwara, M.R. Montminy, and R.H. Goodman. 1993. Phosphorylated CREB binds specifically to the nuclear protein CBP. Nature 365: 855-859.

Dai, P., H. Akimaru, Y. Tanaka, D. Hou, T. Yasukawa, C. KaneiIshii, T. Takahashi, and S. Ishii. 1996. CBP as a transcriptional coactivator of c-M yb. Genes \& Dev. 10: 528-540.

Eckner, R., M.E. Ewen, D. N ewsome, M. Gerdes, J.A. DeCaprio, J.B. Lawrence, and D.M. Livingston. 1994. M olecular cloning and functional analysis of the adenovirus-associated 300-kD protein (p300) reveals a protein with properties of a transcriptional adaptor. Genes \& Dev. 8: 869-884.

Eckner, R., J.W. Ludlow, N.L. Lill, E. Oldread, Z. Arany, N. Modjtahedi, J.A. DeCaprio, D.M. Livingston, and J.A. M organ. 1996a. Association of p300 and CBP with simian virus 40 large $T$ antigen. Mol. Cell. Biol. 16: 3454-3464.

Eckner, R., T.-P. Yao, E. Oldread, and D.M. Livingston. 1996b. Interaction and functional collaboration of p300/CBP and bHLH proteins in muscle and B-cell differentiation. Genes \& Dev. 10: 2478-2490.

El-Deiry, W.S., T. Tokino, T. Waldman, J.D. Oliner, V.E. Velculescu, M. Burrell, D.E. Hill, E. Healy, J.L. Rees, S.R. Hamilton, K.W. Kinzler, and B. Vogelstein. 1995. Topological control of p21 expression in normal and neoplastic tissues. Cancer Res. 55: 2910-2919.

Hal evy, O., B.G. N ovitch, D.B. Spicer, S.X. Skapek, J. Rhee, G.J. Hannon, D. Beach, and A.B. Lassar. 1995. Correlation of terminal cell cycle arrest of skeletal muscle with induction fo p21 by MyoD. Science 267: 1018-1021.

Hall, P.A., P.J. Coates, B. Ansari, and D. Hopwood. 1994. Regulation of cell number in the mammalian gastrointestinal tract: The importance of apoptosis. J. Cell Sci. 107: 35693577.

Inokuchi, H., S. Fujimoto, T. Hattori, and K. Kawai. 1985. Tritiated thymidine radioautographic study on the origin and renewal of secretin cells in the rat duodenum. Gastroenterology 89: 1014-1020.

Jonsson, J., U. A hlgren, T. Edlund, and H. Edlund. 1995. IPF1, a homeodomain protein with a dual function in pancreas development. Int. J. Dev. Biol. 39: 789-798.

Kamei, Y., L. Xu, T. Heinzel, J. Torchia, R. Kurokawa, B. Gloss, S.C. Lin, R.A. Heyman, D.W. Rose, C.K. Glass, and M.G. Rosenfeld. 1996. A CBP integrator complex mediates transcriptional activation and AP-1 inhibition by nuclear receptors. Cell 85: 403-414. 
Kwok, R.P., J.R. Lundblad, J.C. Chrivia, J.P. Richards, H.P. Bachinger, R.G. Brennan, S.G. Roberts, M.R. Green, and R.H. Goodman. 1994. N uclear protein CBP is a coactivator for the transcription factor CREB. Nature 370: 223-226.

Lee, J., K.M. Galvin, R.H. See, R. Eckner, D. Livingston, E. Moran, and Y. Shi. 1995a. Relief of YY1 transcriptional re pression by adenovirus E1A-associated protein p300. Genes \& Dev. 9: 1188-1198.

Lee, J.E., S.M. Hollenberg, L. Snider, D.L. Turner, N. Lipnick, and $\mathrm{H}$. Weintraub. 1995b. Conversion of Xenopus ectoderm into neurons by neuroD, a basic helix-loop-helix protein. Science 268: 836-844.

Lee, J.S., R.H. See, T. Deng, and Y. Shi. 1996a. Adenovirus E1A downregulates cJun- and JunB-mediated transcription by targeting their coactivator p300. Mol. Cell. Biol. 16: 4312-4326.

Lee, J.S., X. Zhang, and Y. Shi. 1996b. Differential interactions of the CREB/ATF family of transcription factors with p300 and adenovirus E1A. J. Biol. Chem. 271: 17666-17674.

Lopez, M.J., B.H. Upchurch, G. Rindi, and A.B. Leiter. 1995. Studies in transgenic mice reveal potential relationships be tween secretin-producing cells and other endocrine cell types. J. Biol. Chem. 270: 885-891.

Missero, C., E. Calautti, R. Eckner, J. Chin, L.H. Tsai, D.M. Livingston, and G.P. Dotto. 1995. Involvement of the cellcycle inhibitor Cipl/WAF1 and the E1A-associated p300 protein in terminal differentiation. Proc. Natl. Acad. Sci. 92: 5451-5455.

Mutoh, H., B. Fung, F. N aya, M.-J. Tsai, J. Nishitani, and A.B. Leiter. 1997. The basic helix-loop-helix transcription factor BETA2/NeuroD is expressed in mammalian enteroendocrine cells and activates secretin gene expression. Proc. $\mathrm{N}$ atl. Acad. Sci. 94: 3560-3564.

N aya, F.J., C.M.M. Stellrecht, and M.-J. Tsai. 1995. Tissue-specific regulation of the insulin gene by a novel basic helixloop-helix transcription factor. Genes \& Dev. 9: 1009-1019.

Naya, F.J., H. Huang, Y. Qiu, H. M utoh, F. DeM ayo, A.B. Leiter, and M.-J. Tsai . 1997. Diabetes, defective pancreatic morphogenesis, and abnormal enteroendocrine differentiation in BETA2/NeuroD-deficient mice. Genes \& Dev. 11:23232334.

Perkins, N.D., L.K. Felzien, J.C. Betts, K. Leung, D.H. Beach, and G.J. N abel. 1997. Regulation of N F-кB by cyclin dependent kinases associated with the p300 coactivator. Nature 275: 523-527.

Puri, P.L., M.L. Avantaggiati, C. Balsano, N. Sang, A. Graessmann, A. Giordano, and M. Levrero. 1997. p300 is required for MyoD-dependent cell cycle arrest and muscle-specific gene transcription. EMBO J. 16: 369-383.

Sartorelli, V., J. Huang, Y. Hamamori, and L. Kedes. 1997. Molecular mechanisms of myogenic coactivation by p300: Direct interaction. Mol. Cell. Biol. 17: 1010-1026.

Scaglia, L., C.J. Cahill, D.T. Finegood, and S. Bonner-Weir. 1997. Apoptosis participates in the remodeling of the endocrine pancreas in the neonatal rat. Endocrinology 138: 1736-1741.

Sosa-Pineda, B., K. Chowdhury, M. Torres, G. Oliver, and P. Gruss. 1997. The Pax4 gene is essential for differentiation of insulin-producing beta cells in the mammalian pancreas. Nature 386: 399-402.

St-Onge, L., B. Sosa-Pineda, K. Chowdhury, A. M ansouri, and P. Gruss. 1997. Pax6 is required for differentiation of glucagonproducing al pha-cells in mouse pancreas. Nature 387: 406409.

Wang, J. and K. Walsh. 1996. Resistance to apoptosis conferred by $\mathrm{Cdk}$ inhibitors during myocyte differentiation. Science 273: 359-361.

Yuan, W., G. Condorelli, M. Caruso, A. Felsani, and A. Gior- dano. 1996. Human p300 protein is a coactivator for the transcription factor MyoD. J. Biol. Chem. 271: 9009-9013.

Zhang, J.J., U. Vinkemeier, W. Gu, D. Chakvravarti, C. Horvath, and J.E. Darnell. 1996. Two contact regions between Stat1 and CBP/p300 in interferon $\gamma$ signalling. Proc. Natl. Acad. Sci. 93: 15092-15096. 


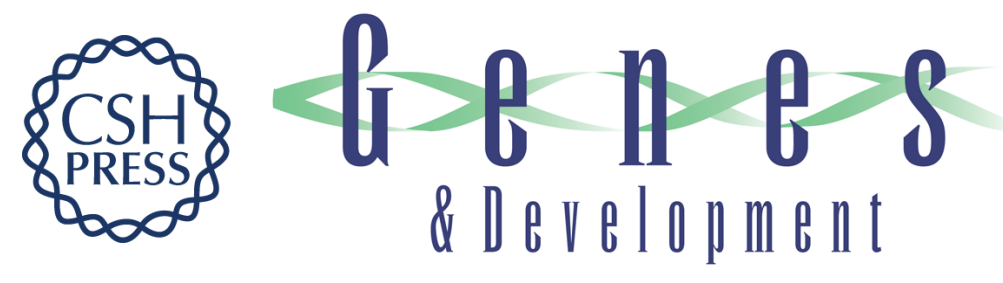

\section{The basic helix-loop-helix protein BETA2 interacts with p300 to coordinate differentiation of secretin-expressing enteroendocrine cells}

Hiroyuki Mutoh, Francisco J. Naya, Ming-Jer Tsai, et al.

Genes Dev. 1998, 12:

References This article cites 36 articles, 22 of which can be accessed free at: http://genesdev.cshlp.org/content/12/6/820.full.html\#ref-list-1

License

Email Alerting Receive free email alerts when new articles cite this article - sign up in the box at the top Service right corner of the article or click here.

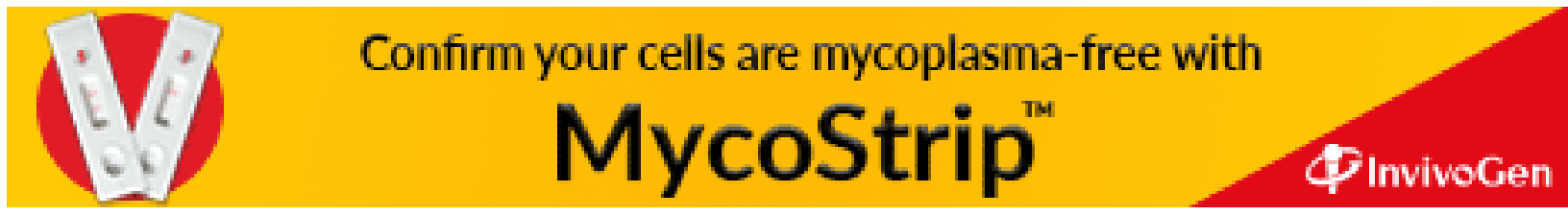

